\title{
La relación entre la Iglesia católica y el Estado colombiano en la asistencia social, c. 1870-1960
}

\begin{abstract}
Castro, Beatriz. La relación entre la Iglesia católica y el Estado colombiano en la asistencia social, c. 1870-1960. Cali: Universidad del Valle, 2014.

En un esfuerzo acabado por mostrar la complejidad de las relaciones entre la Iglesia y el Estado, Beatriz Castro se adentra en terrenos poco explorados por la historiografía colombiana. Se trata de una historia que no insiste en estudiar la secularización como un proceso lineal de escisión entre la Iglesia y el Estado, sino que de manera renovada explora a la Iglesia en sociedad y, para ello, recupera la experiencia de unas religiosas misioneras de voto simple, cuyo modelo de organización facilitó la adaptación de los objetivos de la congregación francesa a las necesidades administrativas de un Estado que buscaba modernizar las prácticas asistenciales a finales del siglo XIX.

La exhaustiva investigación sobre el encuentro del Estado colombiano con la Congregación de las Hermanas de la Caridad de la Presentación se muestra como la suma de complejas relaciones sociales, intereses económicos y coyunturas políticas que cristalizaron las formas de protección social en distintas regiones colombianas.
\end{abstract}

En un período que abarca casi cien años, el libro reconstruye, de manera minuciosa, el andamiaje administrativo que modernizó el incipiente sistema de beneficencia. Con claridad, Beatriz Castro apunta que las religiosas de la congregación femenina francesa, en colaboración con los médicos, actualizaron los métodos y las técnicas del servicio hospitalario y de atención social. Esta es una de las aportaciones del libro en la que me quiero detener, pues si bien, en el cultivado tema de la profesionalización del servicio hospitalario, el protagonismo de los médicos ha tenido un peso significativo, con estos antecedentes, el libro que ahora reseñamos abre un enfoque que complejiza la participación de otros grupos sociales en el proceso de la modernización de la asistencia y de la profesionalización de la atención a los enfermos. Así, el campo de estudio recibe un notable impulso al reconocer la labor de las religiosas, que fueron técnicamente competentes, hábiles administradoras y dedicadas misioneras.

La labor de las ambulancias instaladas por las hermanas en los campos de enfrentamientos bélicos sentó las bases para articular la ayuda humanitaria en las guerras de fin del siglo XIX en Colombia. En un servicio ambulante, de campamentos improvisados con unos cuantos animales para garantizar la 
alimentación, el abasto de drogas, gasas, frazadas, agua y jabón, las Hermanas forjaron el servicio médico neutral en la Guerra Colombo-peruana y en la Guerra de los Mil días. Poco a poco, las hermanas consiguieron la legitimidad de atender por igual a liberales y conservadores, a civiles y a militares. Por la transmisión de conocimientos en los cuidados y auxilio de los enfermos, esta orden de religiosas fue precursora de la profesionalización de la enfermería en Colombia. El cuidado del enfermo como una tarea especializada para las mujeres, también, estuvo marcado por la práctica de la enfermería que las hermanas llevaban a cabo en los hospitales administrados por ellas.

Otro acierto de la autora consiste en destacar las transformaciones del marco institucional y entreverarlas con el diseño de la política asistencial colombiana. Esta es una forma sugerente de mostrar el paulatino proceso de centralización administrativo del Estado moderno, pues a diferencia de los postulados que plantean la centralización de funciones del Estado en cuyo eje están las organizaciones de un gobierno secular, Beatriz Castro demuestra que también el Estado le concede a las religiosas, por lo menos hasta la década de los cuarenta del siglo XX, un lugar conspicuo en la construcción de políticas sociales y muestra que solo a partir de los años treinta, en aras de la modernización de la asistencia y de la mano del proceso de secularización del Estado, otras organizaciones, por ejemplo las de los trabajadores o las de los médicos y las enfermeras, disputaron la legitimidad de asistir a los enfermos y de formar recursos humanos en hospitales y escuelas de medicina y de enfermería. Por lo anterior, si el lector busca un acercamiento al proceso de expansión de las funciones del Estado, la lectura de este libro es indispensable.

Como la primera institución de beneficencia de carácter regional que se fundó en Colombia en 1869, la Junta de Cundinamarca fue un modelo que retomaron otros departamentos para articular el sistema asistencial; asimismo, la relación que estableció la Junta con la congregación religiosa en 1873, también sería un modelo que se replicaría en otras regiones y con otras organizaciones religiosas. El carácter embrionario de la política social colombiana visto a partir de la relación de dos organizaciones representantes del Estado y de la Iglesia, justifica la pertinencia de un estudio meticuloso de los encuentros y desencuentros que trazaron la práctica asistencial y definieron una especie de afrancesamiento de este sistema, no solo por la influencia de los médicos colombianos formados en París que se integraron a la Junta, sino por las labores prácticas que las hermanas instituyeron en los establecimientos a partir de los conocimientos adquiridos en Francia.

Un prolijo análisis de las formas contractuales entre la Junta y las hermanas, confirma que la periodización de las relaciones entre la Iglesia y el Estado que elabora Castro Carvajal, no puede estar desprovista de un concienzudo contexto político económico, que puede parecer parco respecto de los datos que se retoman de cada contrato, pero según expone la autora son referentes, minúsculos, pero nunca invisibles, de relaciones que se reinventan según el valor que cada época otorga a las formas de asistencia social.

Por esto Beatriz Castro se detiene en la formalidad de los contratos que definieron la llegada de las seis primeras hermanas a Colombia y de los servicios que prestarían en los hospitales y los hospicios. Explica que la estructura de 
los contratos retomó aspectos estipulados en los convenios que firmaban otras comunidades religiosas, como las de las Hijas de la Caridad de San Vicente de Paúl, pero advierte que la reformulación de estos acuerdos en Colombia ajustó las funciones y responsabilidades de las hermanas y del Estado para cumplir con el servicio que demandaba específicamente la sociedad colombiana. Así, por ejemplo, con los ajustes contractuales, se entreteje el parteaguas de la reforma administrativa de la asistencia trazada en la ordenanza núm. 51, que cambió en 1920 la manera como el Estado debía referirse al servicio que brindaban las hermanas para dar paso a una nueva concepción acuñada en el vocablo de asistencia pública. La estructura contractual también respondió a la especialización de funciones en el ámbito de la asistencia, así en 1930, las labores que desempeñaban las religiosas eran cada vez más específicas. La década de los cuarenta marcó, en la estructura contractual, la reforma que modificaría sensiblemente, la relación con las comunidades religiosas, pues entre otros aspectos, la Junta debió considerar, de acuerdo con la legislación laboral colombiana, el concepto de seguro en las contrataciones, además de que las religiosas fueron consideradas contratistas y no empleadas de la Junta.

La historia de la expansión de las hermanas en Colombia rompe de manera fresca y aventurada con las historias institucionales y limitadas a las capitales o a las grandes ciudades. La destreza de la autora para mirar a través de la expansión de ciertas políticas sociales el territorio colombiano se plasma en el estupendo recuento de las religiosas: quiénes son, cuántos años tienen, qué tipo de actividades realizan, en qué departamentos se ubican y otros números más, que se presentan como referencias cuantitativas que confirman la compleja manufactura de una historia que combina el análisis de los datos numéricos con la interpretación cualitativa.

Cuando se conocen las oportunidades que los gobiernos consideran en momentos específicos para construir ciertas políticas, se pueden entender mejor los resultados de estas decisiones. De las elecciones y sus ambientes, la autora relata que si a finales del siglo XIX la Junta General de Beneficencia de Cundinamarca contrató a la congregación francesa para que atendiera a los enfermos y administrara los hospitales en Colombia, entre 1940 y 1960, las condiciones del país cambiaron notoriamente y los médicos pudieron oponerse al control administrativo que las religiosas detentaban en los hospitales. Asimismo, si a finales del siglo XIX la influencia de las formas de asistir a la población llegaban de Francia, en el siglo XX, el apoyo internacional que recibieron de algunos proyectos financiados por los organismos internacionales, como la Fundación Rockefeller, fueron más eficaces para desplazar a las religiosas de la administración de los servicios de salud y de asistencia.

Precisar linderos temporales para el caso colombiano representa un paso generoso que traza puntos de partida para la comparación entre diversos modelos y procesos de la construcción del Estado social en América Latina. Esperamos que en el capítulo de lo que quedó por hacer, considerando los sugerentes planteamientos que hace Beatriz Castro en esta investigación y que se suman a otras de envergadura para el tema, se retomen los trabajos acotados por regiones o países que han caracterizado la historiografía sobre el Estado social y se posicione un debate acerca del carácter mixto de las aportaciones de organizaciones 
laicas y religiosas, públicas y privadas que han sido significativas en la construcción de la protección social en América.

La investigación de Beatriz Castro tiene un sólido sustento en fuentes diversas de archivos públicos y privados, en el vasto universo de documentos, destacan aquellos que nos permiten ver los rostros de los hombres y las mujeres que forjaron en el quehacer cotidiano la asistencia social, según las relaciones que establecieron las hermanas con los soldados heridos en combate, con los enfermos y los infectados en brotes epidémicos, con los jardineros que cultivaban las tierras del Hospital de San Juan de Dios, con los médicos y las enfermeras y también con las autoridades políticas de distintos gobiernos locales. El libro supera atinadamente la perspectiva "confesional" de la Iglesia católica para acercar al lector a una historia de experiencias que entresaca de reglas y contratos, de diarios de guerra, de memorias, cartas y expedientes de estudiantes y de beneficiarios, además de la consulta en los diarios y gacetas. Por lo exiguo de los escritos de estas religiosas misioneras, las referencias y los diarios que Beatriz Castro consultó para esta investigación son un privilegio que realza la riqueza documental de su trabajo.

El libro cumple con la expectativa de recorrer paso a paso las relaciones entre la Iglesia y el Estado; cumple con creces el propósito de explicar la construcción de la asistencia social colombiana; cumple con el diálogo riguroso que las historias complejas establecen con la metodología y los planteamientos teóricos, y cumple ininterrumpidamente, capítulo a capítulo, con el lector crítico que puede cuestionarse, junto con la autora, por la participación continua de las organizaciones religiosas en la continua formación del Estado.

María Dolores Lorenzo Río ${ }^{1}$

Profesora e investigadora de El Colegio Mexiquense, Zinacantepec-México madolores@gmail.com

1 Magíster y Doctora en Historia. 